\title{
Robotics Training of Science and Arts Center Teachers: Suleymanpasa/Tekirdag Case
}

\author{
Aytekin Erdem \\ Correspondence: Aytekin Erdem, Vocational School of Technical Sciences, Tekirdag Namik Kemal University, 59030 \\ Suleymanpasa, Tekirdag, Turkey.
}

Received: January 6, 2019

doi:10.11114/jets.v7i7.3943
Accepted: May 15, 2019 Online Published: May 20, 2019

URL: https://doi.org/10.11114/jets.v7i7.3943

\begin{abstract}
The aim of this study is to evaluate the opinions of the Science and Arts Center (SAC) teachers regarding the in-service training course on "Robotics Education". In regards to this, the teachers were expected to evaluate their thoughts and expectations on the robotic education and how much of their expectations were met at the end of the training process. The study has an action research design in which the qualitative data collection tools are used. The study group consists of 9 teachers working at the SAC. For the study, semi-structured forms were used as data collection tools. The data were evaluated with the content analysis method, first in terms of the codes then by the creation of themes. The results of the analyses showed that teachers were satisfied with the training, the perceptions on engineers regarding the task changed, that interest in robots increased and that by understanding the basic operating logic of the robot, they gained self-confidence in regards to performing basic tasks. In line with these results, it is recommended that application-oriented and project-based robotics training is given to teachers.
\end{abstract}

Keywords: robotics training, teacher, in-service training, STEM

\section{Introduction}

Today, the rapid development of technology makes people, who are the source of knowledge-based society, more equipped, but further increases the necessity of possessing knowledge of technology. In this respect, it is seen how important it is to educate individuals who can produce technology and use it in all areas of life (Ugurlu, 2009). Therefore, it is important for teachers, who are expected to train individuals, to be able to use technology effectively and to be able to integrate technology in to their lessons (Akkoyunlu, 1996) hence the need arises for teachers to possess this knowledge and skills. Teachers are also more willing to use technology effectively as a result of the increase in technological equipment and widespread use of technology. In this context, it is important to examine teachers' use of technology in schools and evaluate the results (Sert, Kurtoglu, Akinci \& Seferoglu, 2012).

To concretize the content of abstract learning using new technologies, it is necessary for visual and auditory elements to be a part of the learning process therefore technology-supported execution of educational activities has become mandatory (Altun, Yucel \& Ergun, 2015). The ability of teachers to add technology to the learning-teaching process is important in terms of educating individuals who will have the ability to use technology (Ugurlu, 2009). For this reason, teachers need to be competent in integrating technology in to their courses and taking advantage of technology.

Until recently, computers and web technologies were used for technology in science education in Turkey. However, recently, the use of "robotics" technology in science and technology education has become more widespread. This technological innovation has gained an important place in science and technology education, especially in science and engineering education throughout the world (Koc, \& Boyuk, 2013, cited Cameron, 2005). Robotics is a technological field that enables the design and implementation of robots in many areas and can be defined on a whole as work and techniques that have the functionality to replace people in the manufacturing and service industries (Koc \& Boyuk, 2013, cited URL-1, 2011). While robots are mostly used in industries requiring advanced technology, Makeblock, Lego, etc. robotic sets are prepared in accordance for the use of all individuals over the age of four. Robot training sets can be used for educational purposes and it is indicated that they can also be used in Science, Technology, Engineering and Mathematics Education (STEM) (Ucgul, 2013). Activities with robotic sets contribute to the learning of individuals' robot building, algorithmic thinking, collaborative work, creativity and problem solving, as well as their scientific method, programming logic and engineering design processes. As a result, for students to develop their 
knowledge-based thinking skills, especially in teaching processes supported with an interdisciplinary collaborative training-teaching model, it can be said that the use of robotic activities such as Makeblock, Lego, etc., are of great importance. This technological project assumes that students, who will shape our future, have a very important role in the progress and development of countries; therefore they should have an education of high quality in line with scientific and technological developments, and the use of robot technology will make significant contributions to this process (Zengin, 2016).

If robot design and implementation is based on a real life problem and carried out within the context of STEM; it is emphasized that students will play an important role in developing twenty-first century skills such as critical thinking, creating practical solutions to problems, gaining experience through hands on learning, collaboration, discovering their own abilities, leadership skills, scientific thinking, adaptation skills, entrepreneurship, curiosity and imagination, communication skills, access and use of knowledge, development of technology usage levels, and increasing tendencies for the use of technology (Tezel \& Yaman, 2017, cited Bybee, 2010a; Koc \& Boyuk, 2013, cited Costa \& Fernandes, 2004). In order for the students' robotics education to become more sufficient, it is first important to know the opinions and attitudes of the teachers towards this training.

There are studies in the field that reveal teachers' views on robotics education. For their research, Zhou, Yuen, Popescu, Guillen \& Davis (2015) organized a professional development workshop to integrate robotics with the curriculum of primary and secondary schools. After the workshop, teachers stated that their interest in robotics education had increased and that their concerns about this education had decreased.The workshop also presented strategies to integrate robotics in to the school curriculum. Khanlari \& Mansourkiaie (2015) carried out studies to see if primary and secondary education teachers perceived robotics as a useful tool for STEM education or not. Teachers who participated in the study stated that they perceived robotics as having the potential to facilitate learning of science and technology related subjects but that they did not perceive it as a useful tool for teaching and learning mathematics. Kim, Yuen, Hill, Dashi \& Thai (2015), by engaging in pre-service robotics training to prepare primary school teachers, they kept them busy with STEM and studied the teaching and learning process of teachers. During the evaluation at the end of the course, they found that teachers' emotional involvement in STEM improved significantly. As a result, it was found that teachers' behavioural and cognitive efforts in STEM were influenced. Al-Mouh, Al-Khalifo, Al-Ghamdi, Al-Onaizy, Al-Rajhi, Al-Ateeq\& Al-Habeeb (2016), report the results of a professional development workshop on advanced information processing technologies for high school and secondary school teachers. At the end of the workshop, according to the teachers' assessment, the workshop was successful and the teachers expressed their satisfaction with the workshop in general and their desire to participate in future workshops in order to advance their knowledge of computing. Through their Arts \& Bots project, Hamner, Cross \& Zita (2016) trained 38 teachers from various disciplines in robot design projects to be implemented in the classroom. With a few years of consecutive courses, teacher training has improved and they have explored the development process of teacher experience in their studies. In their studies, Kucuk \& Sisman (2017) aimed to reveal the experiences of the teachers in the teaching of one-on-one robotics with primary school students. The teachers stated that the process of robotic teaching allows students to develop their imagination, provided an environment of play and entertainment, and enabled students to develop their own products. Chalmers (2017) in his research reports on a robotic based university social assistance program aimed at encouraging students' interest in the field of STEM. After the workshop organized within the framework of the program, teachers stated that they helped them develop their knowledge and confidence while implementing their efforts in robotic-based STEM activities. In addition, teachers shared ideas with their friends about adding students to STEM activities as a result of the development of robot-building and programming skills. Jaipal-Jamani \& Angeli (2017) emphasize in their research that engaging primary school teacher candidates in robotics in the context of STEM education in the scientific methods course, contributed to their self-efficacy, science knowledge and computational thinking skills.

Today, efforts to recognize and implement STEM education are increasing. One of the training units interested in STEM education is SAC. In order to improve education, various technological devices are obtained for these units and are trying to be made beneficial for students' education. In this study, the evaluation of the in-service training program carried out for willing teachers to introduce and program the Lego Mindstorm EV3 Robot Training Kit at the Suleymanpasa/Tekirdag SAC was evaluated by teachers. Before this research, within the scope of the In-Service Training Programme of the Ministry of National Education, only teachers employed in the fields of technology in vocational and technical education high schools had been trained in robotics. In order to carry out the in-service training course performed for this research, permission was obtained by contacting the relevant unit in the Ministry of National Education by the Suleymanpasa SAC administration regarding the opening of the robotics training courses for SAC teachers. Prior to this research, a study stating the views of teachers on robotics did not exist because teachers were not able to receive robotics education without the permission of the Ministry of Education. In order to eliminate this gap in 
literature, the eager SAC teachers were given training in robotics and the teachers' views on the robotics training prior to and after the course were investigated. In addition, for the study, the impressions of the participants in the robotics education were determined prior to the course then these impressions were compared with the teachers' views after the course and examined as to whether there was any difference between these views.

\subsection{The Importance and Purpose of the Study}

At SACs where the education of gifted students takes place, the use of robotic training kits is an important issue regarding the students acquiring of 21st Century skills. For this reason, SAC teachers must acquire knowledge and skills on robotics training sets. In the literature, no research has been conducted on the views of SAC teachers regarding robotics education. Therefore, it was thought that the study would fill an important gap in its field and potentially lead other studies to be carried out. On the other hand, the voluntary participation in the research of teachers from various branches shows that the teachers were very keen to prepare a technological learning environment for gifted students. It was assumed that the in-service training program would contribute to the professional development of these teachers. The study is also important in this respect. By utilizing these views of the teachers on robotics education, subsequent pedagogical development of teachers may be carried out with more ease. Therefore, it was assumed that the study would contribute to the literature. It was also believed that, knowledge of teachers' views from different branches on robotics education would have an effect on the development of the learning environment for talented students at SAC in various fields of intelligence (i.e. verbal, social, naturalistic, kinesthetic and rhythmic intelligence). For example, after having received training in robotics education, a music teacher came to the conclusion that robotics technology could be made use of in their lessons. Therefore it became evident that students can increase their musical creativity through the use of robot sets in their music education. On the other hand, academicians interested in teacher training can take advantage of the results of this study and organize professional development programs for teacher training. Teachers from various branches working at SAC may wish to participate in professional development programs on robotics education after reading this study. In addition, it was thought that those who have been educated in areas other than science and technology may now have knowledge on the relationship of robot technology with STEM education as a result of having read this article. In this respect, the aim of this study was to determine the views of SAC teachers who participated in the in-service training course on robotics education. In this context, whether or not the course met the expectations of the teachers, benefits of the education for teachers, the changes in teachers' perceptions towards engineering, and teachers' views on the relationships between science, technology, engineering and mathematics were attempted to be put forward. For this purpose, the research questions were determined as follows:

1. What are the expectations of the teachers attending the robotics training course and were these expectations met?

2. What are the gains of the participating teachers?

3. What are the opinions of the participating teachers on the engineering profession before and after the course and are there any changes in their opinions post-course?

4. What are the teachers' views on the concepts and the links between the concepts of STEM before and after the course?

5. What are the teachers' views after the course on the link between robotic education and the concepts of STEM?

\section{Method}

\subsection{Research Model}

For this purpose, the study was carried out in the technical/scientific/collaborative action research model using the qualitative data collection tool. The aim of this approach is to try and evaluate the application in a predefined theoretical framework. Accordingly, under the guidance of a researcher who has knowledge and skills within the theoretical framework, the practitioner can apply a new approach and the application process can be analyzed by the researcher and the evaluation of the application can be realized (Yildirim \& Simsek, 2016).

\subsection{Study Group and Process}

The study group consisted of 9 teachers teaching various branches working during the 2016-2017 Academic Year at Suleymanpasa SAC, which is in the city of Tekirdag. As shown in Table 1, the teachers were ranged from six years to 21 years and above in terms of seniority with a majority of 16-20 years seniority. In terms of educational background, four of the teachers have a bachelor's degree and five of them have a master's degree. In order to ensure confidentiality and to behave in accordance with ethical rules, the participating teachers were coded as T1, T2, T3,..., T9. 
Table 1. Characteristics of Participants

\begin{tabular}{|c|c|c|c|}
\hline \multirow{4}{*}{ Gender } & Characteristic & Participants & Frequency \\
\hline & Female & - & - \\
\hline & Male & T1-T9 & 9 \\
\hline & Total & & 9 \\
\hline \multirow{6}{*}{ Seniority } & $0-5$ years & - & - \\
\hline & $6-10$ years & $\mathrm{T} 4$ & 1 \\
\hline & $11-15$ years & $\mathrm{T} 3$ & 1 \\
\hline & $16-20$ years & $\mathrm{T} 1, \mathrm{~T} 2, \mathrm{~T} 5, \mathrm{~T} 6, \mathrm{~T} 7$ & 5 \\
\hline & 21 years and over & $\mathrm{T} 8, \mathrm{~T} 9$ & 2 \\
\hline & Total & & 9 \\
\hline \multirow{9}{*}{ Branch } & Biology & T9 & 1 \\
\hline & Geography & T3 & 1 \\
\hline & History & $\mathrm{T} 1$ & 1 \\
\hline & Music & T5, T6 & 2 \\
\hline & Turkish Language and Literature & $\mathrm{T} 2$ & 1 \\
\hline & Special Education & T8 & 1 \\
\hline & Primary School Teaching & $\mathrm{T} 7$ & 1 \\
\hline & Psychological Counselling and Guidance & $\mathrm{T} 4$ & 1 \\
\hline & Total & & 9 \\
\hline \multirow{3}{*}{ Educational Background } & Bachelor's Degree & T2, T4, T6, T9 & 4 \\
\hline & Master's Degree & $\mathrm{T} 1, \mathrm{~T} 3, \mathrm{~T} 5, \mathrm{~T} 7, \mathrm{~T} 8$ & 5 \\
\hline & Total & & 9 \\
\hline \multirow{4}{*}{ Teaching Hours at SAC } & $6-10$ hours & T9 & 1 \\
\hline & 11-15 hours & $\mathrm{T} 4$ & 1 \\
\hline & 16-20 hours & $\mathrm{T} 1, \mathrm{~T} 2, \mathrm{~T} 5, \mathrm{~T} 8$ & 4 \\
\hline & 21-30 hours & T3, T6, T7 & 3 \\
\hline
\end{tabular}

Table 2. Distribution of the activity topics

\begin{tabular}{lc}
\hline Topics & $\begin{array}{c}\text { Duration } \\
\text { (hour) }\end{array}$ \\
\hline Preliminary test & 1 \\
EV3 Brick Use & 1 \\
EV3 Motors & 2 \\
EV3 Sensors & 2 \\
EV3 Interface & 1 \\
EV3 Entry/Exit Connections & 2 \\
EV3 Software Use & 2 \\
EV3 Introduction to Programming & 2 \\
Ultrasonic Sensor and Programming & 2 \\
Ultrasonic Sensor and Programming Application & 2 \\
Colour Sensor and Programming & 2 \\
Colour Sensor and Programming Application & 2 \\
Gyro Sensor and Programming & 2 \\
Gyro Sensor and Programming Application & 2 \\
Infrared Sensor and Programming & 2 \\
Infrared Sensor and Programming Application & 2 \\
Assessment and Evaluation (Examination) & 1 \\
\hline Total (hour) & 30 \\
\hline
\end{tabular}

\subsection{Scope of In-Service Training Program and Course Procedure}

The content of the training was prepared based on the 'EV3 Mindstorm Lego Robot Programming' robotics training kits and in line with the in-service course program criteria of the Ministry of National Education. The in-service training 
program consists of 30 hours in total and lasts for five days. The scope and schedule of the programme (how many hours each activity would be held for) was given in detail to the participating teachers prior to the course (Table 2). During the course, responsive robots (line, sound and light sensitive, etc.) were designed using the basic concepts of robotic science and with the help of the basic elements used in robot construction (motors, sensors, micro-controllers, etc.). The teachers who participated in the study had no previous experience with robotics practices. Instructors provided guidance to teachers during the course, corrected their mistakes where necessary, and asked questions for guidance purposes in order to take the next step. In addition, instructors helped assemble the parts when the teachers had difficulty assembling mechanical parts of the robot.

\subsection{Data Collection Tools and Data Collection}

The data were collected with semi-structured interview forms prepared by the researcher. Interview questions prepared by scanning the literature in order to obtain opinions on robotics education were formed by benefitting from the views of two experts from the field of Educational Sciences. The pilot was carried out with two teachers who were not participants in the research, where three questions were included in the first of the final forms, and seven questions were included in the last. The views and opinions of the teachers working at SAC on their expectations from the in-service training, the duty of the engineer and how the concepts of science, technology, engineering and mathematics relate to each other were all examined through the questions included on the interview form prior to the course. Responses to interview questions were received in writing from the participants. As for on the post-course interview form, there are questions included about whether the course meets with expectation, the teachers' benefits from the course, opinions on the relation between the concepts of science, technology, engineering and mathematics, any changes in teachers' thoughts towards the engineering profession after the activity, whether or not teachers felt like engineers throughout the course, whether they would design robotics after the course and questions about links between robotics education and the concepts of science, technology, engineering and mathematics. Teacher opinions were received in writing for this form as well.

\subsection{Data Analysis}

Research data was analyzed with content analysis. Research reliability is ensured by supporting consistency with multiple encoders in the data analysis process and by detailed description of the data collection and analysis stages. As the final stage, the data are presented in the tables with frequency and percentage ratios. In order to increase the validity and internal reliability of the findings, direct references to teachers' views are included. The number of frequencies and the number of participants could be varied as a teacher indicated more than one opinion to a question.

\section{Findings}

In this section, the findings and comments obtained from the interviews with teachers in relation to the in-service training with robotic training kits can be found. The presentation of the findings is based on the analysis of the data taken before the course and then teacher's views obtained from after the course.

\subsection{Analysis of the Data Obtained Prior to the Course}

The analysis of the data on the thoughts of teachers prior to the robotics training is presented in Table 3-5. Results of the analyses of expectations from teachers prior to the course can be seen for teachers responsible for different educational branches.

Table 3. Teachers expectations of the robotic training

\begin{tabular}{llcc}
\hline Codes & Participants & f & $\%$ \\
\hline Experimental knowledge and skill & T1, T2, T3, T6, T7 & 5 & 62.5 \\
Knowledge on robotic technology & T6 & 1 & 12.5 \\
Learning of robotic software & T4, T5 & 2 & 25 \\
Non-codifiable & 2 & & \\
\hline Total & & & 100 \\
\hline
\end{tabular}

As shown in Table 3, it is understood that most teachers want to acquire experiential knowledge and skills from the training (75\%) and learn robotic software (25\%). In fact, the thoughts of teachers with T1 and T6 codes support this expectation:

T1: To reach acquired and experiential knowledge that will allow me to gain access to a more advanced level of the information and information processing.

T6: To increase my knowledge and skills on robotics.

The results of the analysis on what teachers think about the concept of engineering and how they define it prior to the training can be seen in Table 4. 
Table 4. Teachers' views regarding the duty of an engineer

\begin{tabular}{llll}
\hline Codes & Participants & $\mathrm{f}$ & $\%$ \\
\hline Design objects of daily life & T1, T2,T3,T6 & 4 & 33 \\
Produce technological products & T1,T4,T6 & 3 & 25 \\
Plot and plan & T3,T5,T7 & 3 & 25 \\
Design and implement & T1,T2 & 2 & 17 \\
Non-codifiable & 2 & & 100 \\
\hline Total & & & \\
\hline
\end{tabular}

According to the analysis results obtained from Table 4, 33\% of teachers expressed that they consider the task of an engineer to be designing objects in daily life, $25 \%$ to be producing technological products, $25 \%$ to plot and plan and $17 \%$ to be to design and implement. Below are some of the examples of teachers' views on the engineering profession.

T2: The engineer makes the design and carries out the execution.

T3: The engineer plots, plans and performs; constructs the future, is the building, structuring, and planning profession.

T6: Engineers produce technical and technological products using basic sciences.

Teachers' views on the relationship between science, technology, engineering and mathematics are presented in Table 5.

Table 5. The way teachers relate science, technology, engineering and mathematics to one and other prior to the course

\begin{tabular}{llll}
\hline Codes & Participants & $\mathrm{f}$ & $\%$ \\
\hline These concepts are integrated & $\mathrm{T} 1, \mathrm{~T} 3, \mathrm{~T} 5$ & 3 & 60 \\
$\begin{array}{l}\text { They are necessary scientific branches for product development and } \\
\text { production }\end{array}$ & $\mathrm{T} 2$ & 1 & 20 \\
$\begin{array}{l}\text { Basic concepts } \\
\text { Non-codifiable }\end{array}$ & $\mathrm{T} 6$ & 1 & 20 \\
\hline Total & 5 & & \\
\hline
\end{tabular}

In Table 5, teachers' perceptions of the link between science, technology, engineering and mathematics concepts are given. Attention is draw to the fact that the majority of teachers (60\%) perceptions are that these concepts complement each other and are integrated. T1, T2 and T3 coded teachers' opinions on this subject explain this perception:

T1: Science, technology, engineering and mathematics concepts are used in all fields of medicine, energy, robotics and mechanics.

T2: The most important scientific branches for the establishment of an industry, product development and production.

T3: Each is like a puzzle piece that complements each other; if one is missing, it becomes more difficult to get the complete result. We can also compare it to the steps of stairs. Mathematics and science develop engineering and engineering subsequently develops technology.

\subsection{Analysis of Data Obtained after the Course}

Analysis of data on teachers' thoughts on robotic education after the training is presented in Table 6-11.

Answers to the question: "Did this course meet your expectations?"

Table 6. Teachers' opinions with respect to their expectations of robotics education

\begin{tabular}{llcc}
\hline Codes & Participants & f & $\%$ \\
\hline Met & T1, T2, T3, T4, T6, T8, T9 & 7 & 78 \\
Partially met & T5 & 1 & 11 \\
Not met & T7 & 1 & 11 \\
\hline Total & & & 100 \\
\hline
\end{tabular}

According to Table 6, the majority of teachers (89\%) stated that the in-service training met with expectations prior to the course. One teacher stated that the expectations of the education were not met. It was understood that the T7-coded teacher whose expectations were not met did not participate in the exercises. Therefore, it can be assumed that the teacher had not benefitted from the course much.

In Table 7 results of the analysis indicating knowledge and skills teachers gained through the robotics training can be seen. 
Table 7. Gains of teachers after robotics education

\begin{tabular}{llcc}
\hline Codes & Participants & $\mathrm{f}$ & $\%$ \\
\hline Learning the basic/working principles & $\mathrm{T} 1, \mathrm{~T} 2, \mathrm{~T} 4, \mathrm{~T} 6, \mathrm{~T} 7, \mathrm{~T} 8, \mathrm{~T} 9$ & 7 & 30 \\
Operation logic of robots/Program logic & $\mathrm{T} 1, \mathrm{~T} 2, \mathrm{~T} 3, \mathrm{~T} 6$ & 4 & 16.5 \\
Increasing interest/the happiness of bringing out the product & $\mathrm{T} 3, \mathrm{~T} 4, \mathrm{~T} 6$ & 3 & 12.5 \\
Gaining basic practises & $\mathrm{T} 4, \mathrm{~T} 9$ & 2 & 8.2 \\
Providing psychomotor skills & $\mathrm{T} 2, \mathrm{~T} 9$ & 2 & 8.2 \\
Contribution to daily life & $\mathrm{T} 8$ & 1 & 4.1 \\
Learning from scientific research & $\mathrm{T} 2$ & 1 & 4.1 \\
Complete missing information & $\mathrm{T} 9$ & 1 & 4.1 \\
Ability to use information in different situations & $\mathrm{T} 6$ & 1 & 4.1 \\
Understanding algorithm logic & $\mathrm{T} 2$ & 1 & 4.1 \\
Creating awareness & $\mathrm{T} 3$ & 1 & 4.1 \\
Non-codifiable & 1 & & 100
\end{tabular}

According to Table 7, teachers stated that after the robotics training course, they learned the basic principles of robots/working principle, the robot's program logic, that their interest in robots increased, and they were happy to put forth products. T4 and T8 coded teachers expressed their thoughts on the benefits of the training that they participated in:

T4: I learned basic programming knowledge at a cognitive level. I felt that I was emotionally capable at the basic level. I already enjoyed dealing with mechanical tasks; so it was a fun training to participate in from which I learned knowledge on an area of my interest.

T8: At a cognitive level, I learned about the characteristics of robotic system components and about the field of study. On an emotional level, various ideas began to emerge about what robotic systems would contribute to my daily life. On a kinesthetic level, I learned how to use robotic systems and circuits by doing it hands on.

The analysis of the data obtained after the robotics training to determine whether or not the teachers felt like engineers during the training process is realized in Table 8.

Table 8. Whether or not teachers felt like engineers during the robotic training process I... like an engineer.

\begin{tabular}{llrr}
\hline Codes & Participants & $\mathrm{f}$ & $\%$ \\
\hline Partially felt & T3,T4,T8,T9 & 4 & 45 \\
Felt & T2,T6 & 2 & 22 \\
Didn't feel & T5,T6 & 2 & 22 \\
Felt like an engineer's assistant & T1 & 1 & 11 \\
Non-codifiable & 1 & & \\
\hline Total & & & 100 \\
\hline
\end{tabular}

According to Table 8, 67\% of teachers felt like engineers as a result of the training they received. The participating teachers may have thought this because they realized that engineering tasks can be completed when necessary theoretical knowledge is obtained and reinforced with these tasks. The T4-coded teacher expressed his idea about how he felt like an engineer after the training he attended:

T4: I didn't feel that much like an engineer. But I thought of different ideas. I want to develop these ideas.

In Table 9, views on changes in teachers' perceptions towards engineering post-training can be seen.

Table 9. Changes in teachers' views on engineering perceptions after the robotics training

\begin{tabular}{llll}
\hline Codes & Participants & $\mathrm{f}$ & $\%$ \\
\hline Interest/curiosity increase & T1, T4, T8 & 3 & 30 \\
Change occurred & T8, T9 & 2 & 20 \\
Appreciation/respect increase & T1, T3 & 2 & 20 \\
Perception did not change & T5, T6 & 2 & 20 \\
Discovered different aspects of engineering & T4 & 1 & 10 \\
Non-codifiable & 2 & & \\
\hline Total & & & \\
\hline
\end{tabular}


According to Table 9, 80\% of teachers stated that their interest and respect for robot technology had increased as a result of the training, that there had been a change in their perceptions towards engineering and that they had discovered different aspects of engineering. $20 \%$ of the participants expressed that the perceptions on engineering they had had before the training did not change. T8 and T9 coded teachers stated that they experienced a change in their perceptions about the engineering profession after the training they attended as follows:

T8: There was some change. I didn't think it was that comprehensive before. It didn't grab my attention. I think that as a result of my training in an area of interest, engineering is a complicated field; it is an expertise in which science and mathematics are involved extensively.

T9: Before the course, my knowledge of the application of engineering in this field was foggy. I saw that there could be more advanced applications for engineering with applications and program content processing.

Results for the question: "After this course, do you think you will be able to make simple engineering designs?"

Table 10. Teachers' views on making simple engineering designs after the robotics training

\begin{tabular}{llcc}
\hline Codes & Participants & $\mathrm{f}$ & $\%$ \\
\hline I can & T1, T2, T3, T4, T6, T8, T9 & 7 & 87.5 \\
I can't & T5 & 1 & 12.5 \\
Non-codifiable & 1 & & \\
\hline Total & & & 100
\end{tabular}

According to Table $10,87.5 \%$ of teachers stated that they would be able to make simple engineering designs after the course. T2, T4 and T8 coded teachers expressed their thoughts on producing simple engineering designs as a result of the training they participated in as follows:

T2: After this course I can certainly make simple engineering designs because I understand algorithm logic. And science is for all mankind.

T4: As someone who tried to make different designs before, this training has also helped. After this training, I can also use robotics in my designs.

T8: Yes, simply, I think I can make designs according to the flow chart of a project.

Results of teacher's views on the link between the robotics training and the components of STEM; science, technology, engineering and math can be found in Table 11.

Table 11. The way teachers relate the concepts of science, technology, engineering and mathematics to robotics after the course.

\begin{tabular}{llcc}
\hline Codes & Participants & f & $\%$ \\
\hline They are all connected & T6 & 1 & 12.5 \\
Related to mathematics & T2 & 1 & 12.5 \\
Related to science and engineering & T3 & 1 & 12.5 \\
Related to technology & T3 & 1 & 12.5 \\
$\begin{array}{l}\text { Robotics is the common product of the four disciplines / } \\
\text { related to four disciplines }\end{array}$ & T1, T4, T7 & 3 & 37.5 \\
$\begin{array}{l}\text { The software programme is related to mathematics } \\
\text { Non-codifiable }\end{array}$ & T3 & 1 & 12.5 \\
\hline Total & 3 & & \\
\hline
\end{tabular}

According to Table 11, teachers stated that the robotics science of STEM education is a common product of the disciplines of science, technology, engineering and mathematics and that the four disciplines are related. This may be due to the fact that teachers know that robotic science is possible with the contribution of the four disciplines. Thus, T2, T7 and T8 code teachers' opinions on the link between robotics training with the disciplines science, technology, engineering and mathematics support this view:

T2: Building a robot requires engineering knowledge and skills. Robotic science is closely related to mathematics with mathematical logic operators, angles, variables, and calculations. Robotic applications are frequently encountered with in industry and in our daily lives. With the development of the Industry 4.0, software and robotics are entering the everyday life of the end user. The generation of the knowledge era, which is being brought up with the introduction of software education starting in primary school, will change the life of humanity through the Internet of Things.

T7: Robotics education is the field of application for these four branches of science.

T8: The emergence of different products with the technological development of robotic parts in robotics education, the 
formation of technology according to the fields of science and the emergence of technological products as a result of engineering with mathematical formulas.

Results for the question: "Can you explain the relationship between science, technology, engineering and mathematics disciplines and how do you visualize this relationship?"

Teachers answered this question as follows: "It is an integrated relationship; these branches are the positive sciences; science and mathematics develop to create engineering which then creates technology; science and technology, mathematics, and engineering together ensure development, technology provides progress, engineering integrates and mathematics with calculations and input and output routines; math, science, technology and engineering constitute a cluster; the fields of engineering, technology and science with the help of mathematics create a technological product. The drawings of the participants of T1 and T7 support the views that it is an integrated structure of the four disciplines which constitute a cluster.

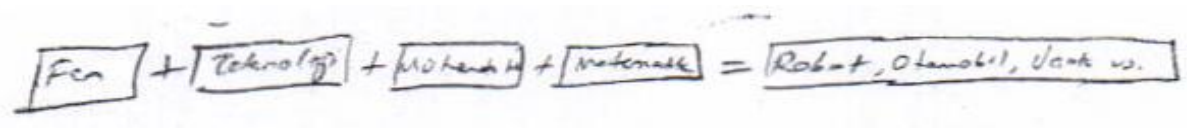

Diagram 1. T1 participant teacher's drawing

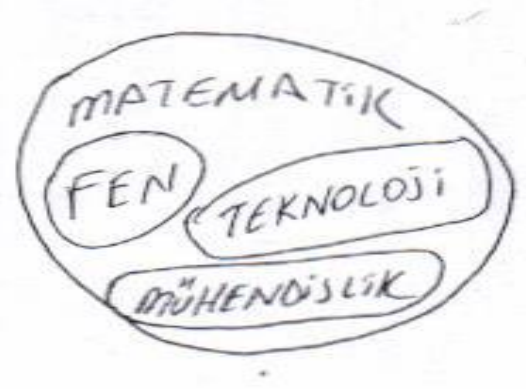

Diagram 2. T7 participant teacher's drawing

\section{Discussion and Conclusion}

In this study, the aim was to determine the views of teachers of various branches of the school on robotics education at Suleymanpasa SAC. Prior to the course, it was observed that $62.5 \%$ of teachers wanted to acquire experiential knowledge and skills, and $25 \%$ expected to learn robotics software. This result can be interpreted as a positive attitude of teachers towards robotics before the course. After the course, the majority of teachers (89\%) stated that the in-service training they attended met the expectations they had before the course. It can be said that the positive attitudes of teachers towards robotics and their intense interest for the duration of the course had an effect on this outcome. From there, it can be interpreted that the course has achieved its purpose, i.e. that teachers have acquired knowledge and skills about the basic operating principles and practices of robotic kits. In order for teachers who have a positive attitudes towards robotic education to gain experiential knowledge and skills in robotics training kits and software, consecutive workshops with project implementation can be held.

Teachers stated that at the end of the training they attended, they achieved the following at cognitive, emotional and dynamic levels. $30 \%$ of teachers said they learned the basic principles and operating principles of robotics, $16.5 \%$ learned the operating logic and program logic, $12.5 \%$ claimed that their interest in robotics increased and that they experienced happiness bringing out products, $8.2 \%$ claimed to have understood the basic practices, $8.2 \%$ gained psychomotor skills, $4.1 \%$ claimed that the training contributes to daily life, $4.1 \%$ claimed to have learned using scientific research, $4.1 \%$ expressed that they learned new information, $4.1 \%$ gained the ability to use information in different situations, $4.1 \%$ said they now understood the logic of algorithms and $4.1 \%$ stated that the training created awareness. From here, it is understood that teachers have gained a lot of from the traning. This result may be due to the teachers' willingness to participate in the robotics training. In addition, it can be said that this result is also because of the fact that the teachers who work at SAC had previously participated in many educational seminars on the subject of technological applications in education and also showed a tendency towards new technologies. In a study conducted by Zhou et al. (2015), it was determined that teachers' interest in robotics education had increased at the end of the workshop. This finding is parallel to the research findings. In the one-to-one robotic education of the primary school students of Kucuk \& Sisman (2017), the teacher candidates expressed that the study provided a product development environment and contributed to the development of the students' psychomotor skills. These findings are also similar to 
the findings of the research. In another study, the fact that at the end of the robotic training, students indicated that they had gained a sense of accomplishment in a task, gained the ability to use their hands and that it had contribution to their everyday life, is also in line with the study's findings (Ziaeefard, Miller, Rastagaar \& Mahmoudian, 2017).

Prior to the course, $33 \%$ of the teachers expressed that they considered the engineer's duty to design everyday objects, $17 \%$ to design and implement objects in to daily life, $25 \%$ to produce technological products and $25 \%$ to plot and plan. Teachers may have thought this way because they have the idea that engineers in various disciplines use scientific knowledge to design various objects to solve problems in everyday life. In another study, when defining the tasks of an engineer, $58 \%$ of the participants focused on engineering products, $21 \%$ on the engineering process and $21 \%$ on the various branches of engineering (Marulcu \& Sungur, 2012). These findings support research results. In another similar study, it is understood that teachers take in to account the engineering disciplines and the skills that engineers should have when describing an engineer's duty (Gul \& Marulcu, 2014). However, it is emphasized that engineering is not only a design process but also a process to achieve rich learning experiences and problem solving skills through scientific inquiry while trying to effectively solve the problems that individuals face (Gul \& Marulcu, 2014, cited Fortuus, Dershimer, Krajcik, Marx \& Mamlok-Naaman, 2004). 80\% of teachers stated that their interest and respect for robot technology increased as a result of the training, that there was a change in their perceptions towards engineering and that they had discovered different aspects of engineering. These results may indicate that the perceptions towards engineering of participating teachers, most of whom are outside the field of science, have changed positively as a result of the training. It can be assumed that teachers will have more positive changes in their perceptions on robotics education and that the change in teacher perceptions will be reflected on to the students immediately.

After the course, to the question: "Did you feel like an engineer?" the majority of teachers responded positively. Although their fields are not closely related to technology, it can be assumed that the teachers were satisfied with the training on a modern technological (robot technology) subject. In addition, it can be said that their role at SAC had an effect on the results. To the question: "Did you change your mind about engineering after the course?" the majority of teachers responded positively. During the training process, it is assumed that, by learning the basic operating principles of robotics and operation of a robot and robotic design, teachers perceptions towards engineering changed for the better. Before the course, it may be assumed that the fact that teachers knew about the link between science, technology and mathematics effected this result. To the question: "After this course, do you think you can make simple engineering designs?" It has been observed that a large majority of teachers (87.5\%) answered "I can." This result may indicate that although the tasks were performed with a single training kit, the teachers were influenced by the robotics training and that there was an increase in their confidence by performing robotic tasks. In a study by Acisli (2016) $75 \%$ of teachers answers affirmatively to the question "Do you think that you could design robots that are suitable for future events?" This finding is similar as well to the research findings.

After the course, to the question: "Can you explain the link between robotics education and science, technology, engineering and mathematics?" $30 \%$ of teachers said that robotics is a common product of the four disciplines, $14 \%$ said that all four disciplines are related to each other, $14 \%$ said that it is related to mathematics, $14 \%$ said that it is related to science and engineering, $14 \%$ said it is related to technology, and $14 \%$ said that the software program is related to mathematics. The fact that teachers prior to the course stated that the concepts of science, technology, engineering and mathematics complement each other and that after the course stated that robotic science is the common product of these four disciplines suggests that teachers have the right thoughts about the nature of robotics. The teachers will reflect their perceptions of robotics to their students, and students with a superior ability will be able to understand robotics more quickly.

To the question: "Could you explain the relationship between science, technology, engineering and mathematics?" $67 \%$ of teachers stated that these concepts are complementary concepts, $16.5 \%$ stated that these concepts are integrated and $16.5 \%$ of them that they are scientific fields that are necessary for product development and production. Smith \& Karr-Kidwell (2000) stated that STEM is based on the integration of four disciplines and that its purpose should be to establish a relationship between disciplines and to achieve a holistic approach that is related, focused, meaningful and purposeful to learners (cited Bozkurt, Yamak \& Kirikkaya, 2016). The research results are similar to this definition. After the course, the answers to the question: "Could you explain the relationship between science, technology, engineering and mathematics and how do you visualize this relationship?" were compared to the answers received before the course and it is observed that the answers are similar to each other. Teachers stated that the concepts of science, technology, engineering and mathematics were complementary and integrated with one and other before the course, and they responded similarly to the same question after the course. From here, it can be said that teachers have knowledge about the relationship between the disciplines mentioned and their perceptions towards STEM are positive. While in some studies, STEM is defined as curriculum and learning activities based on the interconnection of the concepts of science, technology, engineering and mathematics concepts and applications (Cepni, 2017, cited English, 
2016; Sneideman, 2013; Kelley \& Knowles, 2016), in some studies, STEM is defined as teaching any of these areas with problem-based engineering integration (Cepni, 2017, cited Carlson \& Sullivan,1999; Cunningham \& Hester,2007). The research results show parallels with both definitions.

The following suggestions can be made in accordance with the results obtained from the research:

$\checkmark$ Practical robotic training activities should be carried out for willing teachers.

$\checkmark \quad$ Teachers of Science, Mathematics, Computers and Technology should be given practical training on carrying out STEM education for students.

$\checkmark$ In primary and secondary schools, groups of willing students and teachers should be provided with the necessary financial and managerial support to enable them to participate in robot competitions.

$\checkmark \quad$ If science and mathematics classes are carried out in the context of everyday life, it is assumed that the relationship between engineering and technology will be more easily understand by students.

$\checkmark$ If such research is carried out at other SACs, more detailed results on teachers' views on robotics education can be obtained.

\section{Acknowledgements}

To the teachers who participated in the research and to Dr. Mehpare Saka who revised the article, I owe thanks for all of their contributions.

\section{References}

Acisli, S. (2016). Investigation of teachers' perspectives for robotic applications. The Eurasia Proceedings of Educational \& Social Sciences, 4, 395-398.

Akkoyunlu, B. (1996). The impact of computer literacy skills and the integration of current course programs on student achievement and attitudes. Hacettepe University Faculty of Education Journal, 12, 127-134.

Al-Mouh, N., Al-Khalifa, H. S., Al-Ghamdi, S. A., Al-Onaizy, N., Al-Rajhi, N., Al-Ateeq, W., \& Al-Habeeb, B. (2016, September). A professional development workshop on advanced computing technologies for high and middle school teachers. In Information Technology Based Higher Education and Training (ITHET), 2016 15th International Conference on (pp. 1-4). IEEE. https://doi.org/10.1109/ITHET.2016.7760696

Altun, S. A., Yucel, U. A., \& Ergun, E. (2015). Teachers' views on tablet computers. Baskent University Journal of Education, 2(2), 176-187.

Bozkurt-Altan, E., Yamak, H., \& Bulus, K. E. (2016). A proposal for the implementation of the STEM educational approach in teacher education: Design based science education. Trakya University Faculty of Education Journal, 6(2), 212-232.

Cepni, S. (2017). STEM Education from Theory to Practice (1st ed.). Ankara: Pegem Academy.

Chalmers, C. (2017). Preparing teachers to teach STEM through robotics. International Journal of Innovation in Science and Mathematics Education (formerly CAL-laborate International), 25(4), 17-31.

Gul, K. S., \& Marulcu, I. (2014). Examining the perspectives of teachers and teacher candidates on the Lego method for engineering-design and course material. Turkish Studies International Periodical for the Languages Literature and History of Turkic, 9(2), 761-786.

Hamner, E., Cross, J., Zito, L., Bernstein, D., \& Mutch-Jones, K. (2016, October). Training teachers to integrate engineering in to non-technical middle school curriculum. In Frontiers in Education Conference (FIE), 2016 IEEE (pp. 1-9). IEEE. https://doi.org/10.1109/FIE.2016.7757528

Jaipal-Jamani, K., \&Angeli, C. (2017). Effect of robotics on elementary preservice teachers' self-efficacy, science learning, and computational thinking. Journal of Science Education and Technology, 26(2), 175-192. https://doi.org/10.1007/s10956-016-9663-z

Khanlari, A., \& Mansourkiaie, F. (2015, July). Using robotics for STEM education in primary/elementary schools: Teachers' perceptions. In Computer Science \& Education (ICCSE), 2015 10th International Conference on (pp. 3-7). IEEE. https://doi.org/10.1109/ICCSE.2015.7250208

Kim, C., Kim, D., Yuan, J., Hill, R. B., Doshi, P., \& Thai, C. N. (2015). Robotics to promote elementary education pre-service teachers' STEM engagement, learning, and teaching. Computers \& Education, 91, 14-31. https://doi.org/10.1016/j.compedu.2015.08.005

Koc, A., \& Boyuk, U. (2013). Technology-based learning in science and technology education: Robotics applications. 
Turkish Journal of Science Education, 10(1), 139-155.

Kucuk, S., \& Sisman, B. (2017). Experience of teachers in one-to-one robotic teaching. Primary Education Online, $16(1), 312-325$.

Marulcu, I., \& Sungur, K. (2012). Examining the engineering and engineering perceptions of science teacher candidates and their perspectives on engineering design as a method. Afyon Kocatepe University Journal of Science and Engineering, 12(1), 13-23.

Sert, G., Kurtoglu, M., Akinci, A., \& Seferoglu, S. S. (2012, February). A Review of research on teachers' use of technology: A content analysis study. Academic Information'12-XIV. Academic Informatics Conference Papers (pp.1-8). Usak University.

Tezel, O., \& Yaman, H. (2017). A compilation of studies on STEM education in Turkey. Journal of Educational and Instructional Research, 6(1), 135-145.

Ucgul, M. (2013). History and educational potential of Lego Mindstorms NXT. Mersin University Journal of the Faculty of Education, 9(2), 127-137.

Ugurlu, R. (2009). To examine the development of the teacher candidates' formative assessment and evaluation knowledge and skills in the process of the proposed education program within the framework of the technological pedagogical knowledge field (Unpublished Master's Thesis). Marmara University, Istanbul.

Yildirim, A., \& Simsek, H. (2016). Qualitative Research Methods In Social Sciences (10th ed.). Ankara: Seckin Publishing.

Zengin, M. (2016). Views of Primary, Secondary and High School students on the use of robotic systems in Interdisciplinary Education. Journal Of Gifted Education Research, 4(2), 48-70.

Zhou, H., Yuen, T. T., Popescu, C., Guillen, A., \& Davis, D. G. (2015, April). Designing teacher professional development workshops for robotics integration across elementary and secondary school curriculum. In Learning and Teaching in Computing and Engineering (LaTiCE), 2015 International Conference on (pp. 215-216). IEEE. https://doi.org/10.1109/LaTiCE.2015.21

Ziaeefard, S., Miller, M. H., Rastgaar, M., \& Mahmoudian, N. (2017). Co-robotics hands-on activities: A gateway to engineering design and STEM learning. Robotics and Autonomous Systems, 97, 40-50.

https://doi.org/10.1016/j.robot.2017.07.013

\section{Copyrights}

Copyright for this article is retained by the author(s), with first publication rights granted to the journal.

This is an open-access article distributed under the terms and conditions of the Creative Commons Attribution license which permits unrestricted use, distribution, and reproduction in any medium, provided the original work is properly cited. 